\title{
Scripta Nova
}

REVISTA ELECTRÓNICA DE GEOGRAFÍA

Y CIENCIAS SOCIALES

Universidad de Barcelona.

ISSN: 1138-9788

Depósito Legal: B. 21.741-98

Vol. XIX, núm. 510-4

30 de mayo de 2015

\section{Organización, Identidad, Lugar: una poética para los barcos de carga en un mundo globalizado}

\author{
Damian Ruth \\ School of Management, Massey University (Nueva Zelanda) \\ D.W.Ruth@massey.ac.nz
}

\begin{abstract}
Organización, identidad, lugar: una poética para los barcos de carga en un mundo globalizado (Resumen)
\end{abstract}

Este artículo tiene el reto de tratar de expresar, en su mayor parte en términos textuales, una poética de la organización mediante el collage. El argumento implícito es que existe una interdependencia compleja entre los conceptos de organización, identidad y ubicación/lugar, y que ello puede ser examinado de manera productiva mediante una aproximación creativa y poética. Los conceptos de organización, identidad y lugar, a nivel conceptual, material y/o temporal, han sido examinados por muchos teóricos, pero la forma en que aquí se presentan y relacionan entre sí -es decir, una poética que gira en torno al concepto de los cargueros- es nueva. La intención es provocar malestar, pero también alegría y un tipo de reflexión que no encaja fácilmente dentro del núcleo de disciplinas e instituciones. Este texto explota las extrañas y hermosas yuxtaposiciones que pueden ocurrir cuando las ideas de diferentes lugares se encuentran.

Palabras clave: organización, ubicación, identidad, teoría de la organización, investigación de las artes. 
Organization Identity Location: A poetic for cargo carriers in a globalized world (Abstract)

This paper takes up the challenge of trying to express, largely in textual terms, a poetic for organization through collage. The implicit argument is that there is a complex interdependence between concepts of organization, identity and location and that this can be productively examined by a creative, poetic approach. The concepts of organization, identity and location as conceptual, material and/or temporal have being examined by many theorists, but the way in they are presented and related to one another here -that is to say, a poetic that turns on the concept of cargo- is novel. It is intended to provoke unease as well as delight and the sort of reflection that doesn't sit easily within the core of disciplines and institutions. It exploits the awkward and beautiful juxtapositions that can happen when ideas from different places meet.

Keywords: organization, location, identity, organization theory, art research.

Más bien se asemeja más a un bote o a una pintura que a una hipótesis. Susan Krieger.

Si pudiese decirlo, no lo hubiera bailado. Isadora Duncan.

Nunca he hecho una pintura como una obra de arte, es todo investigación. Pablo Picasso.

Este artículo se ofrece como una especie de collage narrativo, en algún punto entre el collage narrativo de Monika Kostera ${ }^{1}$ y el enfoque más tradicional. El collage es tradicionalmente visual y este artículo es, sin embargo, principalmente textual. A pesar de que contiene imágenes, poemas y listas, también se presentan casos a través de la descripción y la argumentación, e incluso la narración. Sin embargo, en general, no existe ninguna posibilidad de que se exprese un argumento sin tener en cuenta cómo se expresa. Este collage explota las ventajas de su forma, las cuales han sido esbozadas por Lynn Butler-Kisber". El collage "refleja la manera en que vemos el mundo con objetos a los que damos sentido, no a través de algo de dentro de ellos mismos, sino más bien a través de la manera en que los percibimos posicionados en relación el uno con el otro"3. En un collage, como sostiene Lawrence S. Rainey, un concepto único y coherente "da forma a las relaciones de yuxtaposición y diferencia"4, y estos fragmentos "trabajan uno contra el otro de forma tan impactante que iluminan la mente" . El collage es ambiguo, esa es la clave. Proporciona maneras de expresar lo inexpresable y da pie a "múltiples posibilidades de interpretación"6.

\footnotetext{
${ }^{1}$ Kostera, 2006.

${ }^{2}$ Butler-Kisber, 2008.

${ }^{3}$ Robertson, 2000, p. 2, cit. en Butler-Kisber, 2008, p. 268.

${ }^{4}$ Rainey, 1998, p. 124, cit. en Butler-Kisber, 2008, p. 268.

${ }^{5}$ Steinberg, 1972, p. 14, cit. en Butler-Kisber, 2008, p. 268.

${ }^{6}$ Butler-Kisber, 2008, p. 269.
} 
Si podemos, al ritmo de lo que sugiere Barbara Czarniawska ${ }^{7}$, pensar en la teoría de la organización como un género literario, sin duda podemos pensar en ella como forma de arte, en este caso, un collage.

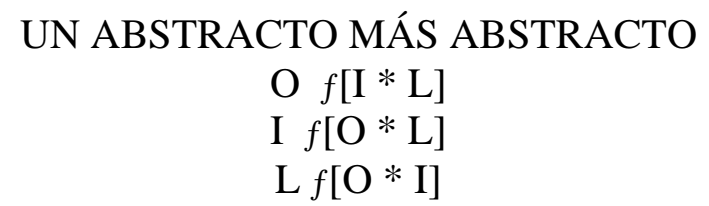

Donde O es organización, I es identidad, y L es lugar ${ }^{8}$

Mi amigo Chris está al teléfono desde Auckland. Hace varios años ambos dejamos Sudáfrica, donde trabajábamos juntos en educación y desarrollo de la organización. Actualmente, doy clases sobre estrategia y cambio organizacional, y Chris se está estableciendo como consultor organizacional. Es difícil. Chris encuentra que no puede "meterse" dentro de las organizaciones en Nueva Zelanda: "aquí todo es suave, nublado, redondeado y cambia de forma constantemente, no hay bordes duros y crudeza. Aquí la gente no toma decisiones de la misma manera". Así es. En Aotearoa, la tierra de la gran nube blanca, la gente se organiza en consecuencia. "Organización", "identidad" y "lugar" parecen ser fenómenos básicos en este proceso. Chris y yo no lo articulamos así conscientemente, pero echamos de menos la rapidez con la que podíamos trabajar en Sudáfrica, incluso entre las diferentes culturas, pues parecía que conocíamos la urdimbre y la trama de aquello con lo que estábamos tratando. Nuestras historias y metáforas funcionaban. Los colores eran diferentes y podíamos distinguir la textura de las cosas. Conocíamos el borde color amarillo y oro contra el azul cobalto y liloso de la montaña. Soy un poeta y, después de haber estado aquí durante unos años, escribí a otra amiga acerca de cómo me estaba costando escribir. Mi amiga, una profesora de inglés, me recordó cómo los escritores escriben desde la tierra. Sus paisajes son la metáfora fundamental.

¿Por qué la gente se organiza en Los Ángeles, Mombasa, Beirut y Yakarta de manera diferente? ¿Por qué y cómo un grupo de abuelas organizan la distribución de alimentos en la comunidad de forma diferente a la que utilizarían un grupo de hombres jóvenes? ¿Es la distinción entre un ejecutivo en el extranjero y un solicitante de asilo en un campamento temporal trivial en el rostro de su humanidad común? Ponderando estas cuestiones, ciertos nodos entran en colisión: organización, identidad, lugar. Se arremolinan, se fusionan, se separan. Parecen generar una problemática, siendo cada uno de ellos una función de los otros dos. ¿Hay agentes o alineamientos o fuerzas que los mantienen en contacto? Tal vez la sangre y el dinero resulten ser metáforasútiles.

La construcción teórica es, ante todo, un acto de la imaginación, un proceso artístico, y la estética es una consideración importante. Así pues, procedamos, de manera poética, a crear una teoría que será tan bella como nos sea posible hacerla.

En julio de 1972, Jared Diamond caminaba por una playa de Papúa, Nueva Guinea, cuando un político local llamado Yali le adelantó. Ambos caminaron juntos y,

\footnotetext{
${ }^{7}$ Czarniawska, 1999.

${ }^{8}$ Location (localización)en el original en inglés.
} 
finalmente, Yali le preguntó: “¿Por qué las personas de raza blanca desarrollaron tanto cargamento (tecnológico y de bienes materiales) y lo trajeron a Nueva Guinea pero nosotros, los de raza negra, tenemos tan poco cargamento propio?". En Armas, gérmenes y acero, Jared Diamond intenta contestar la pregunta que le formuló Yali. Su respuesta se desarrolla en torno a objetos manufacturados y entidades biológicas.

\begin{abstract}
Octubre de 1347. Un carguero genovés está a punto de alcanzar el puerto siciliano de Mesina tras su viaje a Crimea. Eran estos barcos los que estaban haciendo de las ciudades-estado italianas la cuna del Renacimiento. No eran sólo bienes materiales lo que transportaban, sino también métodos y conceptos. Pero hay algo que va mal en estos buques. Se mueven demasiado lentamente. Muy pocos remos tocan la mar. Hay un aire de confusión a su alrededor, se hace evidente incluso antes de haber sido amarrados. Y acto seguido, incluso antes de que haya contacto con un ser humano, los cargueros descargan una carga mortal. A bordo, los marineros están muertos o a punto de morir, con manchas oscuras en sus cuerpos supurando pus y sangre.

La peste ha llegado a Europa. En un día, un total de mil trescientas personas mueren en Avignon, 50.000 muertos en París, 100.000 en Florencia. La bacteria yersinia pestis, traída por las ratas, comienza a alterar la historia de Europa. ${ }^{9}$
\end{abstract}

¿Cómo se puede organizar una plaga? Un problema práctico interesante para un consultor encargado de desarrollar una campaña de marketing viral en un mundo en red y virtual.

Algunos pueden decir que el impulso de la globalización es el comercio, mientras que otros pueden argumentar a favor de un impulso más profundo incluso que la biología, tan profundo que, por no tener pruebas materiales, lo llaman suerte. Su escala temporal es enorme; no está presente sólo "en la sangre", está "en las estrellas".

Tomemos tres entidades: organización, identidad, lugar. No sabemos en qué medida son conceptuales, materiales o temporales. No conocemos su dimensión, escala, procedencia o destino. Si poseen una naturaleza esencial, no tenemos la menor idea de cuál es. Elegimos dos entidades para vincularlas a ellas: sangre y dinero. Seremos como los observadores de Robert Frost, que se sientan en un círculo y hacen suposiciones, mientras el secreto se encuentra en el centro y sabe. Emprendemos un viaje ingenioso, actuando como piratas en el Arca, cargados de metáforas imposibles y memes mágicos, jugando con el montaje, el pastiche, el bricolaje y el collage. Trazaremos mapas de todo lo que podamos -tableros, cosas, ciudades fantasma, sangre, dinero- y luego usaremos nuestros mapas para inventarnos a nosotros mismos.

\title{
“O” es organización
}

El primer paso de la organización es discriminar. Extraemos del total de todas las cosas aquellas que queremos poner en relación las unas con las otras; primero "esto" y "no aquello", seguido por "estas" y no "aquellas". El primer paso para darse cuenta de la propia identidad es discriminar entre uno mismo y el no-mismo. En cambio, el lugar,la ubicación, se basa endiscriminar entre "aqui" en lugar de "alli" o "en otro sitio”. Sin discriminación, sin el reconocimiento de la diferencia, no podemos tener sentido.

\footnotetext{
${ }^{9}$ Bernstein, 2008.
} 
Pero el acto de la discriminación es un complejo misterio y carece de inocencia. Requiere inquisición, un acto de investigación, el intento de resolver un misterio. Madeleine R. Grumet ${ }^{10}$ ha señalado la naturaleza intrusiva y controladora de la etimología de la "investigación" sobre la costumbre y la indagación moralista. La investigación se compone de muchos actos de discriminación. El significado se desarrolla a través de la organización, la identidad y la ubicación/lugar, y los tres elementos existen relacionados entre sí. Necesitamos algún tipo de principio que establezca la organización, la identidad y el lugar. El principio puede ser el caos; la identidad, fragmentada; el lugar, indeterminado u omnipresente.

La discriminación implica correspondencia: ¿cómo sé que "éstos" no son "ésos", a menos que "éstos" tengan algo en común? Por lo tanto, conocer el significado también implica la búsqueda de correspondencias. Se trata de una búsqueda antigua. En el Imperio Antiguo de Egipto, Hapy, con su cabeza de babuino, vigilaba los pulmones; Amset, cuya cabeza era humana, guardaba el hígado; Duamutef, con su cabeza de chacal, vigilaba el estómago y la parte superior del intestino; y Kebehsenuef, cuya cabeza era la del halcón, custodiaba los intestinos menores. Las elaboradas correspondencias desarrolladas en el I Ching resultan familiares en occidente hoy en día. En la Europa temprana, la astrología era respetada como un estudio (ciencia o arte) de las correspondencias. La base conceptual de la herramienta de Myers-Briggs puede rastrearse, a través del trabajo de Jung, en nociones de la Europa temprana sobre los fluidos corporales correspondientes a los humores.

"Asentarse" a menudo significa poner nuestras cosas en sus nuevos lugares. Medimos nuestro grado de asentamiento por la facilidad con la que podemos ubicar nuestras cosas. Estas cosas van de lo mundano y utilitario (“¿dónde está la grapadora?”, “¿has visto el batidor de huevos?") a la fotografía o el adorno de alto valor sentimental. Revelamos nuestras psiques a medida que desempaquetamos y asignamos espacio a los artefactos, y artefactos al espacio. El objeto recontextualizado puede ser un recuerdo de una incursión por parte de uno mismo que no se ha translocalizado (turista) o la evidencia de uno mismo que ha migrado las cosas de una ubicación anterior a una nueva (inmigrante). Puede ser que artefactos totalmente nuevos hayan sido diseñados para sustituir la pérdida total (refugiado). La posición de uno mismo constituye el objeto; la relación entre el objeto y el contexto identifica o contribuye a la identidad de uno mismo. La idea universal de una cosa y una cosa en particular no se relacionan fácilmente. ¿Te preocuparías por un batidor de huevos comprado en un negocio de todo por un dólar? ¿Serviría cualquier foto de nuestra difunta madre?

$\mathrm{Al}$ proceso de poner las cosas en su lugar lo denominamos "organizarse". Organizarse se convierte en un acto de taxonomía frente a la colocación, el desplazamiento y la reubicación. Organizarse requiere comprender y expresar el flujo de las cosas, así como el intento de detener ese flujo, para negociar la primacía de la ubicación -el lugar-por encima de la identidad o viceversa.

Como sugiere Ann Game, en la gestión de las organizaciones, nos fijamos en los elementos fuera de $\operatorname{lugar}^{11}$ y nos preocupamos cuando las cosas van por mal camino.

\footnotetext{
${ }^{10}$ Grumet, 1987.

${ }^{11}$ Game, 1994.
} 
La gestión nunca está muy lejos del control y buscamos dirigir el flujo, incluso arrestarlo. Las Cataratas del Niágara es una temible perspectiva. Sin embargo, no queremos perder la maravilla. Incluso después de que las Cataratas del Niágara, siguiendo los intereses del cargo, hayan sido dragadas, maquilladas, sedimentadas, levantadas, bloqueadas en los cierres, redirigidas y empapadas en oropeles de la ciudad basura y de los visitantes de las instalaciones, se siguen vendiendo como una gran maravilla "natural".

Los objetos de materiales no tienen poder en sí mismos, pero dado que otorgarles poder es nuestra práctica habitual...

Marcel Proust, Le Temps Retrouve, 1927.

La globalización es el proceso por el cual la carga y los iconos de la identidad son transportados de un lugar a otro para crear un entramado de objetos desplazados imbuidos en su procedencia autóctona, una tierra salpicada de objetos extraños, un caleidoscopio de elementos. En este sentido, los seres humanos somos simples objetos movidos por Gaia. La distinción que hacen los seres humanos entre transportar y ser transportado es arrogancia injustificada.

Las organizaciones son momentos de detención en este proceso. Vivimos y organizamos enun paisaje concreto y literal. Lo que hacemos se cimienta en estepaisaje. Dicho paisaje se acerca a nosotros constantemente, todo el día, cada día, y, eventualmente, pasa a vivir dentro de nosotros. Por otro lado, tenemos un mundo interior que imprimimos sobre este paisaje. Dejamos nuestra marca. Nuestro yo interior y el paisaje exterior, en la medida en que podemos distinguirlos, están en un estado constante de reconocimiento y negación mutuo. Cuando nos movemos, rompemos este estado y experimentamos gran desorganización. Solemos perder cosas. Cuando dejamos un paisaje, solemos llevarnos cosas con nosotros. A medida que nos movemos, también lo hace nuestro paisaje. Esto puede suceder de un país a otro, de un lugar/identidad a otro lugar/identidad. Mi oficina de trabajo y mi oficina en casa comparten hasta cierto punto la evidencia de mis otros yoes localizados en otros lugares. Organizamos siempre, organizamos cosas, organizamos un movimiento, organizamos procesos, pero, sobre todo, y a menudo no tan conscientemente, nos estamos organizando a nosotros mismos, nuestros mismos yoes, nuestra identidad.

\footnotetext{
Las cosas que he amado, perdido y dejado atrás en cada marca y hendidura una lírica para el ritual de moverme más allá del parche en el que me encuentro.

Las cosas en la parte de atrás de los cajones, en las grietas de la memoria son punzones agujereando la piel engrosada por tortuosas millas, hombros encogidos contra un viento fresco.
} seguro estoy, si pudiese tenerlas ahora, me ayudarían a encontrar

\begin{abstract}
Algunas cosas pasan a la vista, nunca se han escondido, sólo esperaron hasta que, siguiendo cierto ritmo sagrado acariciaron una mejilla, trabaron un talón, o chillaron maldijeron, cantaron o entonaron un himno.
\end{abstract}

Joyas, documentos en cajas de cartón, un mechón de pelo, fotografías sucias 
constituyen una carga lo suficiente extraña para cualquier viaje

salvo para aquel terreno entre la cabeza, el corazón y el cuerpo

-que sigue siendo un misterio.

\section{"I" es Identidad}

Ahora vivo en un pequeño pueblo en la costa oeste de la Isla del Norte de Nueva Zelanda. La esencia misma de mi ser está cambiando. El carácter de los artefactos en mi escritorio ha cambiado gradualmente en los últimos años. Mi amigo Chris reconocería el paso del viejo orden y la aparición del nuevo; hay menos artefactos de una árida sabana seca y los tipos de estuches han cambiado. Hay una continuidad y un cambio en las fotografías; menos de Sorcha aún bebé y más de ella como una niña, ninguna de mi madre recientemente fallecida -es demasiado pronto aún-, un par de juguetes de niños. Hay un set de sujetalibros que hice con piedra Omarau y conchas de paua incrustadas, un miembro relativamente nuevo de la familia del escritorio. Mi artefacto favorito es una hélice de doble hoja de latón de un mercado de pulgas en Christchurch. No puedo explicar la fascinación que tienen para mí las hélices en general, ni por qué ésta de latón me resulta tan atractiva, pero tiene un merecido valor sentimental: mi madre me la trajo en su único viaje a Nueva Zelanda. Miro este despliegue de objetos, estos iconos de la identidad provenientes de muchos lugares, siempre en un estado de semi-organización, y considero mi carga.

Lo que la gente toma o deja está regido por sus necesidades, miedos y deseos. De igual manera, la asignación de recursos en una sociedad o entre las sociedades avanza según las percepciones de los que tienen el poder de asignar. ¿Qué es lo que se necesita? En un sentido, "OIL" forma una ecología, mientras nosotros buscamos un medio de intercambio. ¿Qué es lo que se necesita y cómo ello es transformado por la translación? Diversas disciplinas han pretendido el trono de la explicación en este sentido. Detrás de las aspiraciones de desarrollo y de las discusiones sobre el propósito de la organización, se suele esconder un marco de suposiciones acerca del homo aconomicus. Azizur R.Khan ha estimado que una mujer adulta en Bangladesh necesita 10,5 metros cuadrados de tela al año para vestirse decentemente ${ }^{12}$ y que una familia de seis miembros necesita dos habitaciones de 14 metros cuadrados cada una ${ }^{13}$. De acuerdo con los cálculos igualmente científicos de la Barioloche Foundation, un africano debería tener 7 metros cuadrados de vivienda, mientras que un Latinoamericano "necesita" 10 iy un habitante de los países industrializados 20 ! $^{14}$ Gilbert Rist señala que este tipo de cálculos se basan en una concepción errónea de lo social como naturalista, "pero la sociedad no puede ser reducida a un zoológico humano y una hipotética 'naturaleza humana' sirve muy poco cuando buscamos

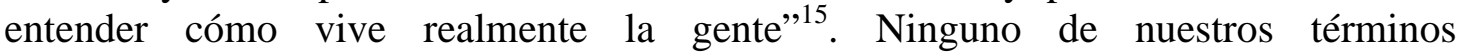
(organización, identidad, lugar) son cuantificables y, sin embargo, hay algún tipo de economía en juego. De diferentes maneras, los jefes "necesitan" alfombras más gruesas y ventanas más grandes que los mecanógrafos.

\footnotetext{
12 Khan, 1977, p. 74, cit. en Rist, 1997, p.167.

${ }^{13}$ Khan, p. 86, ibid.

${ }^{14}$ Khan, p. 86, ibid.

${ }^{15}$ Rist, 1997, p. 168.
} 
En el análisis núcleo-periférico de Ankie Hoogvelt ${ }^{16}$ sobre la arquitectura de las relaciones sociales en el mundo, la distinción no es geográfica, sino que se refiere al lugar de cada cual en la estructura social de la energía y, en consecuencia, de la riqueza. Pero el lugar, la ubicación, está amarrada a la geografía. Zygmunt Bauman ${ }^{17}$ señala que la movilidad del capital no va acompañada de la movilidad de la mano de obra, que está dividida. Hay una jerarquía de movilidad, en la que algunas personas pasan a estar relocalizadas y otras se convierten en refugiadas. En una época en la que, para muchas personas -sobre todo "personas corporativas"-, tantas fronteras son cada vez más permeables y, para tantas personas -especialmente aquellos seres orgánicos pobres y de piel oscura-, los requisitos para la obtención de visados son cada vez más estrictos, la identidad es un modo de organizar el lugar, de igual manera que el lugar organiza la identidad.

Una identidad dislocada dependerá de emblemas y símbolos. Mi esposa es irlandesa y, para ella, un trébol es sólo un cliché trillado. La imagen de un vaso de Guinness no significa "irlandés" para ella. Significa una bebida. Una imagen que representa la quintaesencia irlandesa para ella es el arpa, una imagen que aparece en iconos gubernamentales. Una imagen con muchas más probabilidades de provocarle nostalgia es el bhorhán, el tambor folclórico irlandés. Como sudafricano de nacimiento y de crianza, lo más obvio de los símbolos es la forma en que pueden ser apropiados y cambiados para explotar circunstancias políticas. Son objetos transitorios poderosos. Piensen en Nelson Mandela poniéndose el jersey de rugby con la gacela cuando Sudáfrica ganó la Copa del Mundo en 1994.

No sólo buscamos lugares, los producimos. Aunque Henri Lefebvre ${ }^{18}$ haya hecho de "la producción del espacio" una frase conocida, sus ideas tuvieron una historia más larga y se basaron en una lectura espacial de Marx. La percepción de Lefebvre no sólo dio paso a la "estructura del sentimiento" de Raymond Williams, sino también a la comprensión del espacio cultural como "infraestructura del sentimiento". Trevor Paglen sostiene que, conociendo esto, podemos entender mejor "la manera en que las acciones de cada cual participan en la producción de espacio" "19. La gente no sólo decora el espacio de trabajo que les es asignado. Lo crean.

Nuestra identidad se basa en las fronteras. De hecho, lo que comúnmente vemos como "al borde de nuestro mundo" o "en las fronteras" es central para nuestro mundo. Por lo tanto, la mujer blanca en Sudáfrica considera que la sirvienta negra está al borde de su mundo. Sin embargo, en realidad es un elemento central de su identidad. Puede haber diferentes niveles de conciencia acerca de esto. Es poco probable que la sombra del trabajo de un esclavo en una fábrica de Indonesia se cierna sobre la vida de un adolescente colegial que lleva las zapatillas deportivas que él cosió en el estado de Colorado. ¿Hasta qué punto, tanto literal como metafórico, Vietnam, Afganistán e Iraq existieron en los EE.UU.? ¿Se encuentra Pakistán más dentro de Gran Bretaña de lo que Gran Bretaña se encontraba dentro de Pakistán?

\footnotetext{
${ }^{16}$ Hoogvelt, 2001.

${ }^{17}$ Bauman, 1998.

${ }^{18}$ Lefebvre, 1974.

${ }^{19}$ Paglen, 2008, p. 31.
} 
Podemos expresar ciertos tipos de reclamaciones explícitas y formales con relativa facilidad, por ejemplo la propiedad legal sobre algo. Es un poco más difícil expresar el contenido de las creencias, aspiraciones y aspectos de la identidad, aunque la atribución de etiquetas no lo es tanto (budistas, católicos, africanos). Nuestro comportamiento y el uso de los artefactos revela la naturaleza de nuestras creencias y aspiraciones de forma más precisa que las declaraciones explícitas. A través de los artefactos, revelamos la sustancia de nuestras creencias y aspiraciones y, a menudo, a través de los artefactos, hacemos el seguimiento de nuestro parecido y diferencia, evolución y taxonomías.

El artefacto más esencial es el propio cuerpo. No es de extrañar que las personas traten sus cuerpos con indulgencia, negación, celebración y desprecio. Muchas sociedades perciben el cuerpo como una carga o una ilusión o un lugar donde realizar un nuevo sentido de uno mismo. Hay sistemas de pensamiento que sugieren que la corporización empieza antes que la manifestación física, y hay muchas creencias sobre el cuerpo respecto de la muerte.

Cuando Eva Perón falleció a los treinta y tres años, fue embalsamada para la posteridad. Cuando el Presidente Perón fue derrocado, el nuevo régimen escondió el cuerpo de Eva durante quince años. La mantuvieron en un embalaje marcado como "aparatos de radio" en algún lugar de Buenos Aires. En un momento dado, su cuerpo fue secuestrado y se pidió un rescate por él. Cuando se recuperó, fue trasladado a la embajada en Bonn. Después, fue sepultado en una tumba en Milán y, en 1971, el cuerpo fue devuelto a Juan Perón, que en ese momento estaba exiliado en Madrid. Perón volvió al poder y, cuando murió, el cuerpo de Eva fue enviado de vuelta a Buenos Aires para yacer a su lado.

Fawaz-al-Emari recibió cirujía plástica y sus cuerdas vocales fueron retocadas para que pudiera aparecer como Saddam en desfiles y nadando en el Tigris. Pedro Shapallo pasó la mitad de su vida como Enver Hoxha, el dictador Albano. Alan Fletcher sostiene que "su esposa, sus dos hijas, el cirujano que rehizo su rostro, el sastre y el peluquero que efectuaron la transformación fueron asesinados para preservar la ilusión" ${ }^{20}$. ¿Qué tipo de mapa sería necesario para explicar tal identidad? No cabe duda de que mapear el genoma sería útil.

Lo que en Sudáfrica se llama small-holding se denomina lifestyle block ${ }^{21}$ en Nueva Zelanda. Small holding no tiene necesariamente la connotación de clase que tiene lifestyle block y, de hecho, podría significar un pedazo de tierra pequeño, no muy alto en la escala social. Recientemente vi en un autobús la invitación "Diseña la vida que quieres". Yo apenas puedo llamar al pequeño cuarto de acre en el que vivo lifestyle block pero, a pocos minutos a pie de la playa y al lado una gran reserva natural, proporciona los medios parauna envidiable calidad de vida. He vivido la mayoría de mi vida en una costa, un borde, una frontera de algún tipo. Sobre esta roca he construido mi vida.

\footnotetext{
${ }^{20}$ Fletcher, 2001, p. 338.

${ }^{21}$ N. del T.: Se refiere a una propiedad semi-rural de pequeño tamaño que comprende una vivienda y una parcela de tierra para cultivar a pequeña escala.
} 
Soy el padrino del hijo de Chris y su hija tiene casi la misma edad que la mía. Nuestras familias llegaron con un par de años de diferencia. No tenemos mucho contacto últimamente, pues vivimos en extremos opuestos de la isla.

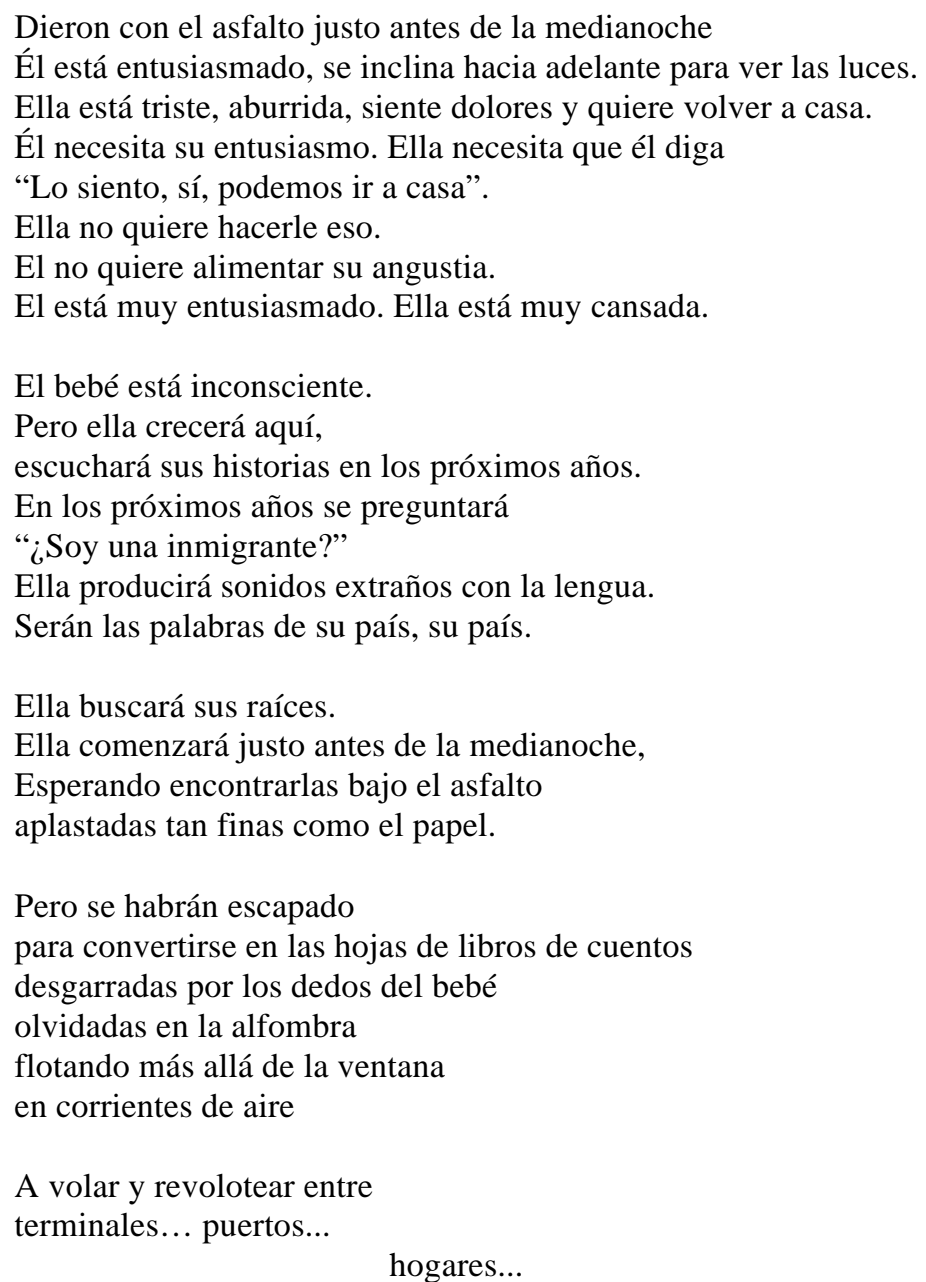

\section{"L" es Lugar}

¿Quién ha movido mis cosas? ¿Y dónde exactamente están mis cosas? ¿Cuál es la diferencia entre vivir en un gran pedazo de tierra y vivir en un lifestyle block? ¿Cómo llegamos a pensar en un lugar como una localización, cómo podemos llegar a considerar una entidad como "una localización"? ¿Qué resultaba nuevo o familiar de Nueva Amsterdam y Nueva York? Como señala Bill Bryson, "en todo el Oeste, las ciudades iban y venían... Iowa vio cómo 2.205 comunidades se transformaban en pueblos fantasma en su primer siglo",22. ¿Siguen flotando sus 2.205 nombres, como tenues fantasmas amarrados, por encima de la tierra sobre la que en algún tiempo yacían las ciudades? ¿Qué significa decir "yo vengo de (una ciudad que ya no existe)?".

\footnotetext{
${ }^{22}$ Bryson, 1996, p. 149.
} 
Tim Robinson ha mostrado que, en la colonización de Irlanda, la creación de mapas otorgó poder a Dublín y creó un doble nivel de conocimientos geográficos, un doble nivel de lenguaje con capas con las que hablar sobre la tierra ${ }^{23}$. El entramado abstracto y matemático de Ordnance Survey entró en conflicto con los mapas locales, nunca dibujados, sino orgánicos, flexibles y en constante cambio, pero llenos de significado para quienes caminaban por aquellas rocas, cruzaban sus ríos, y sabían dónde los antepasados se habían asentado, y dónde sus huesos se asientan aún. A medida que los británicos cambiaban los nombres en Irlanda -unas veces tornándolos anglicismos; otras simplemente sustituyéndolos-, otorgaron nombres a lugares que nunca antes necesitaron nombres, y nunca denominaron lugares que habían sido nombrados siempre. El poder del mapa de Ordnance Survey creció, y sus coordenadas comenzaron a vaciar el significado local de los lugares más recónditos del imperio.

Los nombres de lugares en Sudáfrica también tenían un doble nivel idiomático. Según si uno era inglés o Afrikaans, llamaba a un lugar Springs o Kimberley. Sin embargo, si uno era un negro sudafricano, es probable que fuese de Kwa Thema a Galashewe, porque Springs y Kimberley, al igual que casi todas las ciudades de Sudáfrica, constan de dos ciudades: la "ciudad blanca", que tenía un nombre, y la ciudad negra, a menudo al otro lado de la carretera, río o línea ferroviaria, que se conocía simplemente como "el lugar". Por lo tanto, al mirar el mapa de Sudáfrica antes de 1994, se podría trazar una ruta de Louis Trichardt a Ciudad del Cabo, pasando por Pietersburg, Pretoria, Johannesburgo, Kroonstad, Bloemfontein y Beaufort West. Más tarde, en el Atlas del Times, reimpreso con cambios en el año 2000, se trazaba la ruta de Louis Trichardt a Ciudad del Cabo a través de Pholekwane, Shoshanguve, Mamelodi, Soweto, Maokeng, Manguang y Sidesaviwa. ¿Acaso los lugares van y vienen?

Saber dónde están las cosas y la manera en que las cosas están organizadas es una forma del poder. Los primeros mapas modernos eran secretos del imperio. Cualquiera que fuera descubierto distribuyendo un mapa a una potencia extranjera podía ser castigado con la pena de muerte ${ }^{24}$. En la antigua China, uno de los rituales de la derrota consistía en que los vencidos dieran al conquistador los mapas de su territorio. Hoy en día, los consultores saben que obtener un contrato depende a menudo de ser capaz de seguir el cheque. El organigrama puede estar a disposición del público, pero no siempre muestra claramente las líneas del poder real; el dinero, como la sangre, fluye.

¿Son suficientes nuestras coordenadas de O. I. L.? ¿Podemos detectar pistas? ¿Tenemos suficiente carga, suficiente material para este viaje?

En el acto básico de la creación de mapas geográficos encuentro tres conjunciones: aquella entre el lugar mapeado y el que hace el mapa; otra entre el cartógrafo y el mapa en sí; y por último la conjunción entre el mapa y aquello que ha sido mapeado -esta última, un enfrentamiento que pone a prueba el valor de la primera y la segunda.

Tim Robinson, Setting Foot on the Shores of Connemara. 1996.

El gladiador global mueve sus herramientas a través del espacio; con fibras ópticas tensadas de punto a punto

\footnotetext{
${ }^{23}$ Robinson, 1984.

${ }^{24}$ Harvey, 2000.
} 
afirma que todo tiempo y espacio se han derrumbado, como si el ritmo y lugar de todos estuviesen fijados por las coordenadas de su fantasía.

Pero, ¿qué tipo de mapa es aquel que no registra ni forma ni contorno, ni color, ni olor, pero hace del territorio un espejo de la locura? El exiliado ojo renacentista, movido del "quién" al "a partir de qué punto" es forzado a volver sin descanso a un agujero anclado al cuerpo, donde finalmente, cara a cara, de corazón a corazón, y hombro con hombro, entendemos el espacio entre nosotros.

¿Qué tipo de kilómetro captura el trabajo de un morgen? ¿Qué peso soportaría lo cuántico de la fe? ¿Cómo es uno fiel a aquello meramente mesurable al enfrentarse a una arcada en ruinas derramando piedras sobre líneas que una vez encerraron sueños clamados al cielo, ahora anidados en desgastadas banderas y apenas un suspiro?

Si el tiempo se ha derrumbado, ¿por qué mis brazos anhelan un amante que está sólo a una llamada de teléfono?

Los ojos del cartógrafo que buscan sus coordenadas en la vida de los cuerpos, brillan como almenaras; a diferencia de la visión lacerada la función desgarrada cuya mirada es una medida de control, gestionando el paisaje, precisa en la métrica, marcando influencia, pero, yendo de acantilados colapsados y feroces olas a una vida encasillada de certeza alucinada.

Yo prefiero bailar en la costa de mi vida, dejar que el mar raspe la piel y poros de la suciedad de viajes interiores expulsados por los ríos que vuelven de una tierra que, aquí en su borde, abandona trozos de sí misma en el mar que captura entre las mareas.

Bahía de entrada de arroyo; península, cabecera y saliva: marea convirtiendo a uno en lago y a otro en isla; puente corta canal y rocas salen a la vista; canal corta puente y las islas son desamarradas; un calendario lunar de obras de un acto; un lento deambular del destino como una costa cambiante que toca nuestros corazones para tomarnos, y recordarnos, que nuestras métricas son insensatas sin un cuerpo para romper el silencio de las piedras y bailar al son de las canciones del viento.

\section{Sangre y dinero}

Un artefacto o sustancia quintaescencial de la evolución y la taxonomía es la sangre. Aquí tenemos los cargueros por excelencia. Nuestras creencias sobre la sangre son un registro de lo que tememos y deseamos. Lo que pensábamos sobre la sangre ahora lo pensamos sobre los genes o el ADN. ¿Quién tiene los de quién? No es de extrañar que queramos mapear el genoma. Cuando Goethe observó que "la sangre es un fluido muy especial", estaba hablando como poeta: el acuerdo entre Fausto y Mefistófeles tiene que ser firmado en sangre. Steve Jones señala: 
Disputas de sangre, hermanos de sangre, sangre azul, sangre fría, mala sangre, todas han pasado de la órbita de la ciencia a la de la metáfora. Pero cambia el idioma un poco, sustituye "sangre" con "gen", y de repente nos encontramos en el mundo moderno. Hay una nueva era de la creencia en el poder de la biología y el temor de lo que podemos llegar a encontrar acerca de nosotros mismos. ${ }^{25}$

El autor analiza el santuario budista en la isla sagrada de Miyajima en Japón, que es una especie de oráculo basado en grupos sanguíneos. Las parejas japonesas que planean casarse suelen preguntarse el grupo sanguíneo. La idea de que el grupo sanguíneo determina la personalidad es sólo una versión exagerada de la creencia general sobre lo que los genes pueden hacer. La sangre ha sido asumida como el vehículo de la herencia desde la antigua Grecia. Pero el defecto fatal en la idea de la sangre como portadora de cualidades a medida que una generación sucede a la última no sólo fue observado por Darwin, sino también por el gobierno británico cuando, en 1971, se dispusieron a redefinir la esencia, la sanguis, de ser británico. La ley de Inmigración y Nacionalidad de 1971 tenía un objetivo no mencionado: excluir a los inmigrantes de color mientras se permitía que los sudafricanos blancos, los kenianos y los australianos pudieran volver a lo que muchos veían como su tierra natal. La solución, dice Jones, "era simple, cínica e ingeniosa": la idea de la "patrialidad" residía en la sangre. "La sangre británica... una vez diluida perdió su poder" ${ }^{26}$. Con el paso de los años, cada vez menos ciudadanos de la Commonwealth serían capaces de clamar el ratio vital de sangre realmente británica, transmitida a través de un padre o un abuelo privilegiado. La regla fue aplicada a la inversa en los Estados Unidos. Cualquier persona con un antepasado negro, aunque sea lejano, se definió como negra. Una gota de sangre negra era suficiente para contaminar la línea para siempre: la mancha nunca podría ser limpiada. La regla se originó como una forma de ampliar la población esclava con los hijos ilegítimos de los esclavistas.

Según Jones, la contribución de Mendel fue mostrar que la herencia depende de partículas pasadas de manera inalterada de generación en generación. Él hizo la crucial distinción entre el mensaje -los genes- y el medio, los individuos que las propagan. El mensaje es lo que cuenta; el destino de aquellos que lo diseminen es más o menos irrelevante. Los seres humanos deberían evitar ser arrogantes sobre su papel en Gaia.

La plaga del bacilo yersina pestis utilizó principalmente pulgas y ratas para extender su influencia. Los seres humanos, como artefactos individuales, no resultaron transmisores eficientes, ya que morían demasiado rápido. Sin embargo, su actividad del comercio fue muy útil. Gracias al comercio, la plaga se pudo propagar de Kaffa a Europa, para después ser detenida gracias también al comercio. La fe musulmana dio lugar a un embargo comercial que mantuvo a Europa libre de la yersina pestis durante ocho siglos. Luego, como explica Bernstein, el comercio se reanudó con entusiasmo y la peste volvió con su venganza ${ }^{27}$. Los conductistas organizacionales harían bien en recordar que no sólo la gente se mueve en organizaciones.

\footnotetext{
${ }^{25}$ Jones, 1986, p. 3.

${ }^{26}$ Jones, 1986, p. 13.

${ }^{27}$ Bernstein, 2008, p. 130.
} 
Uno de los grandes proyectos taxonómicos hoy en día es mapear el genoma humano. Dos equipos compiten para completar este mapa, uno motivado por el interés público, y el otro por el provecho a nivel privado; sangre e impuestos, dinero de la sangre. El pacto de Fausto fue un intercambio. La genialidad de Goethe como poeta fue elegir la sangre como medio de abstracción entre el poder y la vida. Otra abstracción preeminente es el dinero. Comerciar con el dinero y la sangre puede ser muy rentable. La sangre puede ser moneda, la moneda puede ser objeto del comercio. Un poco de sangre de los márgenes genera grandes ganancias en la metrópolis, como algunos pueblos indígenas de las Islas Salomón han podido descubrir. El dinero no es la línea inferior sino la punta del iceberg.

Como la sangre, el dinero es otra sustancia por excelencia de la evolución y la taxonomía en torno a la cual coalicionan cuestiones sobre organización, identidad y lugar. Los impuestos son un intento de atenuar las diferencias de riqueza e igualar el flujo de ingresos. Diseminan los activos de las personas dentro del conjunto de la población. En ciertos aspectos, se trata de un intento de forzar al dinero a comportarse de manera sexual. En economía, el proceso se conoce como la redistribución de ingresos; en el campo de la genética, como recombinación ${ }^{28}$. Mientras que Jones hace una conexión entre la sangre y las tasas fiscales en términos de la distribución de la desigualdad, James Buchan ${ }^{29}$ expone la naturaleza del dinero como un medio de transporte, más concretamente, un portador de "deseos congelados". "El dinero se transforma en dinero sólo en el instante que incorpora el deseo"30. Lo que está implícito en el análisis de Buchan es que el dinero realmente se comporta de manera sexual y redistribuye y recombina el deseo.

Entre los artefactos en el escritorio de mi casa se encuentra un vale de 25 centavos del casino Ceasars. Invitado por un colega, jugué a unas pocas máquinas, pero me sentí mucho más interesado en el casino como expresión material del deseo y qué mejor souvenir de mi visita que un trozo de papel cumpliendo las funciones de un vale. Lo dejé antes de que mi dinero se acabase. Fuera del Ceasars, no es más que un pedazo de papel; dentro del Caesars posee, no importa cuan improbable, la promesa de una fantástica riqueza. Me da mucho más placer reflexionar sobre esto que jugar a las máquinas. También tengo en mi escritorio un vale de 10 centavos de Canadian Tire Stores firmado por el Vicepresidente, el Tesorero, el Presidente y el Director Ejecutivo de la empresa. Puede ser canjeado solo con mercancías en tiendas de neumáticos canadienses y podría funcionar como dinero en algunas comunidades canadienses de la misma manera que los moluscos cowrie lo han hecho en las comunidades africanas. Volveremos a los artefactos del escritorio de mi casa. El escritorio que tengo en el trabajo no es tan interesante...

Buchan describe el hallazgo, en un mercado de la calle en Londres, de billetes que ahora tienen un valor emotivo y doloroso, totalmente ajeno a su valor nominal. Pagó veinte libras por un paquete de billetes con el valor nominal de cien coronas. El billete de arriba databa del 1 de enero de 1943, estaba escrito en alemán austriaco y firmado por Jakob Edelstein, el Anciano Jefe del Consejo de los Judíos en el campo de concentración de Theresienstadt en Bohemia. Una escarapela lucía un bonito retrato de

\footnotetext{
${ }^{28}$ Jones, 1986, p. 83.

${ }^{29}$ Buchan, 1997.

${ }^{30}$ Buchan, 1997, p. 12
} 
Moisés con los Diez Mandamientos. Edelstein fue asesinado en Birkenau en 1944. Buchan observa:

\begin{abstract}
Los billetes estaban en la misma relación con la realidad que las postales que algunos prisioneros deportados enviaban desde Polonia: "El viaje fue agotador pero sin incidentes". El fraude y el consuelo inherente a todo el dinero se convierten, en estos Ghettodronen, en puro engaño, pura fantasía. La gente cree en ellos de la misma manera que todos creemos en el dinero, porque sin él no podemos vivir en el mundo, que presiona y se convierte en una prisión en la noche con trenes largos que golpetean en dirección al norte... ${ }^{31}$ Desde nuestra posición ventajosa, podemos ver que el dinero no es ninguna sustancia en particular y puede no ser de ninguna sustancia: aquello que el dinero es puede manifestarse en monedas o proyectiles, cuchillos, sal, hachas, pieles, hierro, arroz, caoba, tabaco, cajas de ginebra; en personas; en una palabra o gesto, papel, plástico, impulsos electrónicos o lingotes de plata ${ }^{32}$.
\end{abstract}

Edward Gibbon comparó la difusión del dinero con la difusión de la escritura: "El valor del dinero se ha saldado con el consentimiento general para expresar nuestros deseos y nuestra propiedad, de la misma manera que las cartas fueron inventadas para expresar nuestras ideas; estas dos instituciones, al dar más energía activa a las facultades y las pasiones de la naturaleza humana, han contribuido a multiplicar los objetos que ellas mismas fueron diseñadas para representar"33. La confusión entre la representación y la sustancia se ha hecho más profunda. Buchan afirma que, según Aristóteles, los seres humanos inventaron el dinero, y, a continuación, las monedas, a fin de hacer posible una división internacional del trabajo. A la luz de Aristóteles y el uso de la metáfora de Buchan para explicar el dinero como una especie de estación ferroviaria de maniobras que está permanentemente y para siempre recibiendo los deseos y sueños de un sinnúmero de personas y enviándolas a destinos insospechados, cada uno de los puntos en el marco de la economía globalizada es una estación ferroviaria de maniobras, despachando sangre/ADNa todo el mundo. Tenemos una sangrienta economía de representaciones, una relación sexual del miedo y el deseo, diseminadas ampliamente en torno a los conceptos de organización, identidad y lugar. Pero ¿quién es el cartógrafo?

La identidad es un cociente de la igualdad; la diferencia y las metáforas de la sangre y el dinero nos dan el tapiz sobre el que se trazan la monotonía, las diferencias y la forma en que están constantemente redistribuidas. Nuestras metáforas sobre la sangre (o el ADN) y el dinero revelan cómo expresamos nuestros temores y deseos.

Cuando entendemos la economía como un discurso de miedo y deseo, podemos comprender mejor el dinero como deseo congelado. Ahorramos y gastamos dinero y, al hacerlo, oscilamos entre el miedo y el deseo. La economía intenta ser abstracta (matemática o puramente métrica) y biológica al mismo tiempo. Si como una ciencia se asentara por ser puramente matemática, la economía sería... matemáticas. La economía también tiene pretensiones de decirnos algo acerca de la vida, la sociedad y el ser humano -recordemos que un africano debería tener 7 metros cuadrados de vivienda, mientras que un latinoamericano "necesita" 10 y un habitante de los países industriales 20-. En la medida en que logra el éxito, la economía se convierte en

\footnotetext{
${ }^{31}$ Ibid, p. 12.

${ }^{32}$ Ibid, p. 16.

${ }^{33}$ Buchan, 1997, p. 19.
} 
filosofía. Pero la economía a menudo intenta ser filosofía científica. Esta es la razón por la cual muchos pronósticos económicos comparten la característica de equivocarse a menudo. La observación irónica de John Gailbraith de que el objetivo de las predicciones económicas es que la astrología tenga un aspecto respetable revela una verdad: tanto la economía como la astrología se fijan en los símbolos con los que damos sentido a las cosas. Comercio, biología, "en la sangre" o "en las estrellas"; la economía no es el descubrimiento de las coordenadas que tan a menudo pretende ser, es el uso de las coordenadas para ayudarnos a mapear dónde estamos y a dónde podríamos querer ir. Tanto la astrología como la economía son a menudo profundamente incomprendidas en este sentido y la autoridad que se atribuye a los economistas y el desprecio hacia los astrólogos oscurecen el hecho de que lo que tienen en común puede ser mayor que lo que las diferencia.

Díganle a la gente de Europa que disfruta comiendo chocolate, que están comiéndose mi carne.

(Victor).

Esta cita está tomada de un artículo periodístico sobre la esclavitud infantil y se refiere el documental de la BBC Esclavitud: una investigación global, co-producido por Brian Woods. En un comunicado personal, Woods aclaró la cita de la siguiente manera: "El Niño que dijo eso se llama Victor. Fue rescatado junto con otros dieciocho niños de la esclavitud en una plantación de cacao, su cita exacta es "el agricultor para el que trabajaba vende chocolate a la gente blanca que lo come, por lo tanto, estoy muy enfadado con ellos, porque he trabajado muy duro, no fui pagado y ellos siguen comiendo ese cacao, se están comiendo mi carne".

Los textos a continuación son respuestas supuestamente verídicas que mujeres de Manchester han escrito en los foros del Organismo de Apoyo al Niño, dentro de la sección "detalles del padre". Hay cientos de listas de "respuestas genuinas" o comentarios "auténticos" sobre temas diversos fluyendo a través de internet.

Con respecto a la identidad del padre de mis hijos gemelos, Makeeshia fue engendrado por Maclearndon McKinley. No estoy segura de la identidad del padre de Marlinda, pero creo que fue concebida esa misma noche.

No estoy segura en lo que se refiere a la identidad del padre de mi hijo, ya que estaba enferma, vomitando por la ventana, cuando fui tomada inesperadamente por detrás. Puedo facilitar una lista de nombres de los hombres que creo que fueron a la fiesta si esto le ayuda.

No sé la identidad del padre de mi hija. Conduce un BMW que ahora tiene un agujero hecho por mi Stiletto en uno de los paneles de las puertas.

Tyrone Hairston es el padre del niño A. Si logra ponerse en contacto con él, ¿puede preguntarle qué hizo con mis cds de AC/DC? El niño B que también nació al mismo tiempo... Bueno, no tengo ni idea.

Mucho de esa noche es borroso. Lo único que recuerdo es que Gordon Ramsey hizo un programa sobre huevos esa noche más temprano. Si me hubiera quedado a ver más TELEVISIÓN en lugar de ir a la fiesta en el número 56 de Miller Street, quizá no hubiese sido fertilizada.

No estoy segura en cuanto a la identidad del padre de mi bebé, después de todo, como cuando una se come una lata de frijoles, no puedes saber seguro cuál hizo que te tiraras un pedo. 


\section{Las taxonomías y genealogías}

¿De dónde viene todo esto? ¿A dónde van todas estas cosas? Discriminación y correspondencia, diferencia y similitud, dependen de las taxonomías y genealogías. De la misma manera que la "organización", la "identidad" y la "lugar" pueden ser tratadas en términos metafóricos y jugar con ellas, también podemos jugar con las taxonomías y genealogías. En esta época de modernidad líquida, podemos proceder como si estuviéramos comenzando en la desembocadura del Ganges (o el Mississippi, el Níger o el Nilo) con la perspectiva de deambular por siempre en las llanuras o subir a las montañas hacia una fuente coherente, o podemos proceder tomando decisiones arbitrarias entre afluentes en dirección a un paso coherente antes de nuestro último derrame en la no diferenciación oceánica.

Cuando nos estamos organizando, en lo que se refiere al lugar, sobre todo en uno nuevo, utilizamos las taxonomías de los objetos y los lugares. Usamos listas. También usamos listas cuando nos estamos organizando temporalmente. Tenemos listas de actividades construidas sobre una taxonomía del tiempo: horas, días, semanas; antes, después, mientras tanto; y así sucesivamente. Las listas pueden ser simplemente una caprichosa forma de delinear los contornos del mundo de cada uno; también pueden confundir las distinciones entre ser y hacer. De The Pillow Book ${ }^{34}$ :

25. Las cosas sobre las que uno está obligado a ser negligente

La observancia de un solo día.

Los preparativos sobre algo que todavía está en el futuro.

Un largo retiro en un templo.

30. Las cosas que suscitan un grato recuerdo del pasado

Malvarrosas secas.

Los objetos que se utilizan durante la visualización de las muñecas.

Encontrar una pieza de color violeta oscuro o material color de uva comprimido entre las páginas de un cuaderno.

109. Las cosas que especialmente atraen la atención de uno en algunas ocasiones

El sonido de los vagones en el primer día del primer mes del año.

El canto de los pájaros en ese día.

El sonido de la tos $-\mathrm{y}$ también, no hace falta decirlo, de un instrumento musical-al amanecer.

140. Las cosas que proporcionan una sensación de limpieza

Copa de barro.

Un nuevo recipiente de metal.

El juego de la luz sobre el agua mientras una la vuelca en un recipiente.

Un nuevo cofre de madera.

141. Las cosas que proporcionan una sensación sucia

Un nido de ratas.

Alguien que tarda en lavarse las manos por la mañana.

Gimoteos blancos, y los niños que gimen mientras caminan.

Los recipientes utilizados para el aceite.

Gorriones pequeños.

\footnotetext{
${ }^{34}$ Sei, 2006.
} 
El Kama Sutra enumera las mujeres con las que está prohibido tener relaciones sexuales en cualquier circunstancia: una leprosa, una lunática, una mujer expulsada de su casta, una mujer que no puede guardar un secreto, una mujer que expresa públicamente su deseo de un hombre, una mujer que es demasiado justa, una mujer que es demasiado oscura,

la mujer que emite un olor desagradable, una mujer que es pariente cercano, una mujer que es una amiga, la mujer que dedica su vida a la religión y la esposa de un familiar, un amigo, un erudito sánscrito o el Rey ${ }^{35}$. El Kama Sutra es un libro de listas comprensivas. Comúnmente considerado como un manual del sexo, rinde tributo a las taxonomías de etiqueta en el servicio del deseo: las listas de tipos de besos, marcas, posiciones, virtudes, esposas, rituales, prohibiciones, permisos, etc. Al estilo de un libro sagrado o un libro de magia, contiene la receta y los pasos. Los libros modernos de autoayuda y del nuevo-yo emulan la misma fe en las taxonomías y las identidades como en "N pasos hacia el éxito" o "¡Ncaminos hacia un nuevo tú!”.

En El idioma Analítico de John Wilkins, Jorge Luis Borges ${ }^{36}$ describe "cierta enciclopedia china", el Emporio Celestial de Conocimientos Benévolos, en la que está escrito que los animales se dividen en:

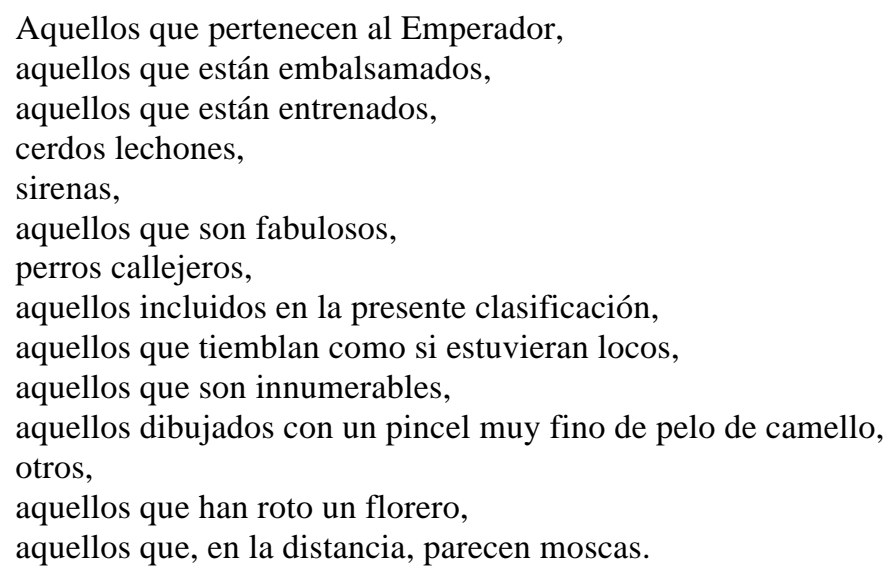

Las taxonomías y los archivadores están relacionados con metáforas de rizoma o tapiz. A lo que se expresa en el tapiz accedemos a través de nuestras taxonomías de la textura. Pero incluso las alfombras mágicas tienen bordes.

\section{Una poética de la organización}

Uno de los principios básicos de la explicación científica es el de la navaja de Occam, denominado así por el lógico medieval William de Occam. El principio de la parsimonia es un principio de economía ontológica: no multiplicar las entidades más allá de la necesidad; "es un principio estético, un criterio para la belleza de las teorías científicas y un axioma fundamental del razonamiento científico" ${ }^{37}$. Según Crispin Sartwell ${ }^{38}$ :

\footnotetext{
${ }^{35}$ Vatsyayana, 1961, p. 36.

${ }^{36}$ Borges, 2000.

${ }^{37}$ Sartwell, 2006, p. 19.

${ }^{38}$ Ibid, p. 19-20.
} 
Fue la estética y no la observación quien refutó a Ptolomeo y llevó a Copérnico. La estética de la ciencia es una estética clásica, una estética de la nobleza, el alcance y la simplicidad. Puede que haya prácticas de explicación que sistémicamente favorezcan explicaciones más elaboradas por encima de otras más sencillas, pero estas nos llevarían a "teorías" que al final nadie podría comprender o hacer uso de ellas. Una ciencia limpia o clásica parece más útil para realizar nuestros deseos, para potenciarnos por encima de nuestro entorno. La Ciencia, en este sentido, sirve a la tecnología, que podríamos definirla como la transformación del medio ambiente y del cuerpo humano al servicio del deseo.

¿Podríamos crear una teoría de la belleza, la elegancia, el alcance y la simplicidad para dar cuenta de la manera en que organizamos nuestra identidad, para dar cuenta de nuestra carga, que constantemente estamos mudando, reorganizando, recreando? ¿Hay un lenguaje para describir cómo la organización, la identidad y la ubicación son las funciones de cada uno? ¿Tal vez cada una sea un holograma de las tres? Quizá se debería recurrir a una gama de diferentes tipo de idiomas. Tal vez, como sostiene Mark Ebers ${ }^{39}$, necesitemos la manera matemática $y$ la poética para entender la organización, la identidad y el lugar.

¿Qué ocurre cuando aplicamos el principio de la parsimonia de un modo poético? Escribo acerca de las cosas que he amado, perdido y dejado atrás. Ese poema es una expresión de los vínculos y sus significados son controlados (en la medida en que pueden ser controlados) por mi secuencia de términos y el uso de conectivos. Ahora entrego la gramática, dejo caer los conectivos, y solo presento una secuencia:

Dinero de sangre. Linaje. Propiedad. Genealogía. Herencia. Valor. Pacto. Intercambio. Red, tapices, rizoma. Patrón. Ritmo. Repetición. Manta. Regalo. Reciprocidad. Hilo. Transferencia. Transfusión. Fungabilidad.

A continuación se muestra un mezquino trato de la organización. Aunque no hay ningún intento de crear una secuencia significativa, algunas secuencias pueden ser distinguidas.

Las organizaciones que

solo existen en láminas delgadas,

mueren a la luz,

sólo existen para un segundo a la vez,

son portátiles,

florecen en luna llena,

son sólo accesibles a través del contacto,

son incapaces de causar daño,

son intrínsecamente peligrosas,

son orbitales,

pueden tejer,

pueden ser conectadas y desconectadas,

han de estar bien pronunciadas,

despiertan de sueños,

nunca revelan su propósito,

\footnotetext{
${ }^{39}$ Ebers, 1985.
} 
son de uso sólo a aves no voladoras, requieren entusiasmo, que no existen, son conocidas sólo por cuadrúpedos, surgen de una discusión entre Jackson, Pollock y Piet Mondrian, despiertan el grato recuerdo del pasado, proporcionan una sensación de limpieza, pertenecen al emperador, son perfumadas, se dibujan con un pincel muy fino de pelo de camello, en la distancia parecen moscas.

La verdadera naturaleza de la teoría es que es estética. Establece su valor en términos de la tríada tradicional de valores humanos: la verdad, la bondad y la belleza. Es una forma de arte. Mi fórmula introductoria no es matemática, sino que utiliza símbolos y convenciones de las matemáticas como una poesía. Cada uno de los términos es una agregación, una especie de conglomerado. He intentado desglosar cada uno de ellos en diferentes términos y reflexionar sobre las taxonomías, las genealogías, la similitud y la diferencia. Parafraseando a Yeats, uno no puede distinguir el transporte de carga de la carga. Quizá nos conviene pensar en términos de flujo. La poética del OIL -y de la sangre y el dinero- puede aclarar lo que Ahrne, Brunsson y Halllström ${ }^{40} 11$ aman los "elementos" de la organización: reglas, número de miembros, jerarquía y sanciones.

En la medida en que puede considerarse como una teoría sobre la organización, la identidad y el lugar, este artículo es como las siglas de su tema: OIL [aceite]. Invita al lector a taxonomizar y rastrear, para así contribuir a otra lista. La buena teoría OIL es viscosa, potencialmente explosiva en una forma refinada, ecológicamente peligrosa.

"Seamos amantes, casaremos nuestra suerte juntos. Tengo algunas propiedades aquí en mi bolso". Así que compramos un paquete de cigarrillos y pasteles de la Sra. Wagner y salimos a buscar América.

Paul Simon, América, 1968.

América no existe, lo sé, he estado allí.

Personaje de la película Mi tío americano (1980) de Alain Resnais.

El mundo necesita cosas bien hechas que muestran un amor de acero y piedra y arcilla. esta escoria en que nos ahogamos nos entrega al infierno donde el celebrar nos pervierte en captar y el abrazo en simbólica ceremonia.

La curva elaborada y el artificio inteligente que arruga la comisura de tu boca que deja caer una bomba en tu vientre que aprieta tu ingle que aligera tu paso no se fabrican en una maquiladora. Es magia del alma dada forma por tiernos dedos.

No importa si se precisó un cincel o un martillo o un cuchillo.

\footnotetext{
${ }^{40}$ Ahrne, Brunsson \& Halllström, 2007.
} 
Tenemos que tomar las cosas con suavidad y sostener las cosas que se deben sostener con cuidado para que podamos seguir los extremos de nuestros nervios para maravillarnos al borde de una hoja.

\section{Bibliografía}

AHRNE, G.; BRUNSSON, N. \& HALLSTROM, K. T. Organizing Organizations. Organization, 2007, 14(5), p. 619-624.

BASBOLL, T. \& GRAHAM, H. Substitutes for Strategy Research: Notes on the source of Karl Weicks's anecdote of the young lieutenant and map. Ephemera theory and politics in organization, 2006, 6(2), p. 194-204.

BAUMANN, Z. Globalization: The Human Consequences. New York: Columbia University Press, 1998.

BERNSTEIN, W. J. A Splendid Exchange: How Trade Shaped the World. New York: Grove Press, 2008.

BORGES, J. L. Jorge Luis Borges: Selected Non-Fiction. Traducido por L.A. WEINBERGER. London: Penguin, 2000.

BRYSON, B. Made in America: an informal history of the English Language in the United States. New York: Avon Books, 1996.

BUCHAN, J. Frozen Desire: An Inquiry into the Meaning of Money. London: Picador, 1997.

BUTLER-KISBER, L. Collage as Inquiry. In KNOWLES, J.G. (ed.). Handbook of the Arts in Qualitative Research. London: SAGE, 2008, p. 265-276.

CLEGG, S.; KORNBERGER, M. \& RHODES, C. Learning/Becoming/Organizing. Organisation, 2005, 12(2), 147-167.

COSTALL, A. \& DREIER, O. Doing things with things: The design and use of everyday objects (Ethnoscapes). Aldershot, UK: Ashgate, 2006.

CZARNIAWSKA, B. Writing Management: Organization Theory as a Literary Genre. Oxford: Oxford University Press, 1999.

DIAMOND, J. M. Guns, germs and steel : a short history of everybody for the last 13,000 years. London: Vintage, 1998.

DOPICO, L. Cartographic Desires: The Map as Symptom. In FERREIRA, C.; OLIVEIRA, M. \& DOPICO, L. Mapas, Cosmogonia e Puntos de Referencia. Centro Galego de Arte Contemporanea / Xunta De Galicia, 2007. 
EBERS, M. Understanding Organizations: The Poetic Mode. Journal of Management, $1985,11(2)$, p. 51-62.

FLETCHER, A. The Art of Looking Sideways. London: Phaidon, 2001.

GAGLIARDI, P. Artifacts as Pathways and Remains of Organizational Life. In GAGLIARDI, P. (ed.), Symbols and Artifacts: Views of the Corporate Landscape. New York: Aldine de Gruyter, 1992, p. 3-13.

GAME, A. 'Matter Out of Place': The Management of Academic Work. Organisation, 1994, 1, p. 47-50.

GRUMET, M. The Politics of Personal Knowledge. Curriculum Inquiry, 1987, 17(3), p. 319-329.

HARMON, K. The Map as Art: Contemporary Artists Explore Cartography. New York: Princeton Architectural Press, 2009.

HARVEY, M. The Island of Lost Maps. New York: Random House, 2000.

HOOGVELT, A. Globalization and the postcolonial world: the new political economy of development. Baltimore, MD: John Hopkins University Press, 2001.

JONES, S. In the Blood: God, Genes and Destiny. London: Flamingo, 1996.

KHAN, A. R. Basic-Needs Target: An illustrative exercise in identification and quantification. In GHAI, D.P.; KHAN, A.R.; LEE, E.L.H. \& ALFTHAN, T. (eds.), The Basic-Needs Approach to Development: Some Issues Regarding Concepts and Methodology. Geneva: International Labour Office, 1977.

KLINGHOFFER, A. J. The Power of Projections: How Maps Reflect Global Politics and History. London: Praeger, 2006.

KOSTERA, M. The Narrative Collage as Research Method. Storytelling, Self, Society: An Interdisciplinary Journal of Storytelling Studies, 2006, 2(2).

LERPOLD, L.; RAVASI, D.; VAN REKOM, J. \& SOENEN, G. Organizational Identity in Practice. London: Routledge, 2007.

MEYER, G. \& GENT, M. Metaphors of management education: casting new light and looking in dark corners. Journal of Management Education, December 2003, 27(6), p. 631-636.

MITCHELL, A. J. Heidegger Among the Sculptures: Body, space, and the art of dwelling. Standford, California: Standford University Press, 2010.

PAGLEN, T. Experimental Geography. In THOMSON, N. (ed.), Experimental Geography: Radical Approaches to Landscape, Cartography and Urbanism. New York: Independent Curators International, 2008. 
PARKER, M. \& THOMAS, R. What is a critical journal? Organization, July 1, 2011, 18(4), 419-427.

RAINEY, L. Taking dictation: Collage, poetics, pathology and politics. Modernism/Modernity, 1998, 5(2), p. 123-153.

RIST, G. The History of Development from Western Origins to Global Faith. London: Zed Books, 1997.

ROBERTSON, B. Why collage? [en línea]. 2000.

http://www.collagetown.com/history01.shtml

ROBINSON, T. Setting Foot on the Shores of Connemara. Dublin: Lilliput Press, 1984.

SARTWELL, C. Six Names of Beauty. New York: Routledge, 2006.

SCHAMA, S. Landscape and Memory. London: Harper Perennial, 2004.

SEI, S. \& KCKINNEY, M. The Pillow Book. Traducido por M. MCKINNEY. London: Penguin Books, 2006.

STEINBERG, L. Other criteria: Confrontations with twentieth-century art. New York: Oxford University Press, 1972.

STRATI, A. The Aesthetic Approach in Organization Studies. In LINDSTEAD, S. \& HOPFL, H. (eds.), The Aesthetics of Organization. London: Sage, 2000, p. 13-34.

VATSYAYANA. Kama Sutra: The Hindu Ritual of Love. New York: Cosmopolitan Kama Shastra Society, 1961.

VERBEEK, P. P. What Things Do. University Park, PA: The Pennsylvania State University Press, 2000.

WOOD, D. Rethinking the power of maps. New York: Guildford Publications, 2010.

(c) Copyright Damian Ruth, 2015.

(C) Copyright Scripta Nova, 2015.

Ficha bibliográfica:

RUTH, Damian. Organización, identidad, lugar: una poética para los barcos de carga en un mundo globalizado. Scripta Nova. Revista Electrónica de Geografía y Ciencias Sociales. [En línea]. Barcelona: Universidad de Barcelona, 30 de Mayo de 2015, vol.

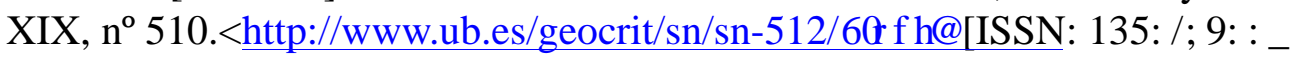

